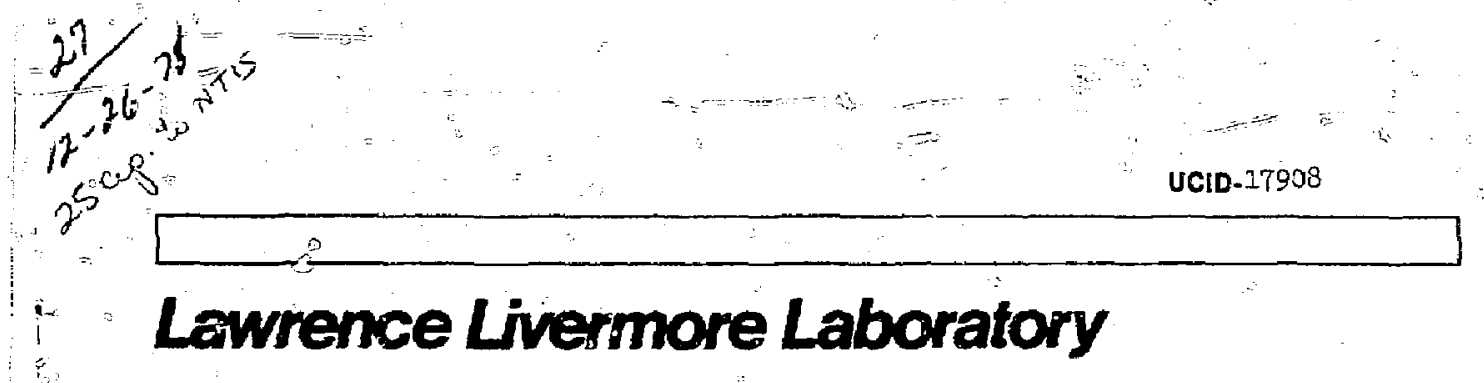

USER'S MANUAL FOR A TWO-DIMEIISTOHAL, GROUHD-WATER FLOH CODE OU THE OCTOPUS COMPUTER WETHORK

Thomas G. Neymik

August 30,1978

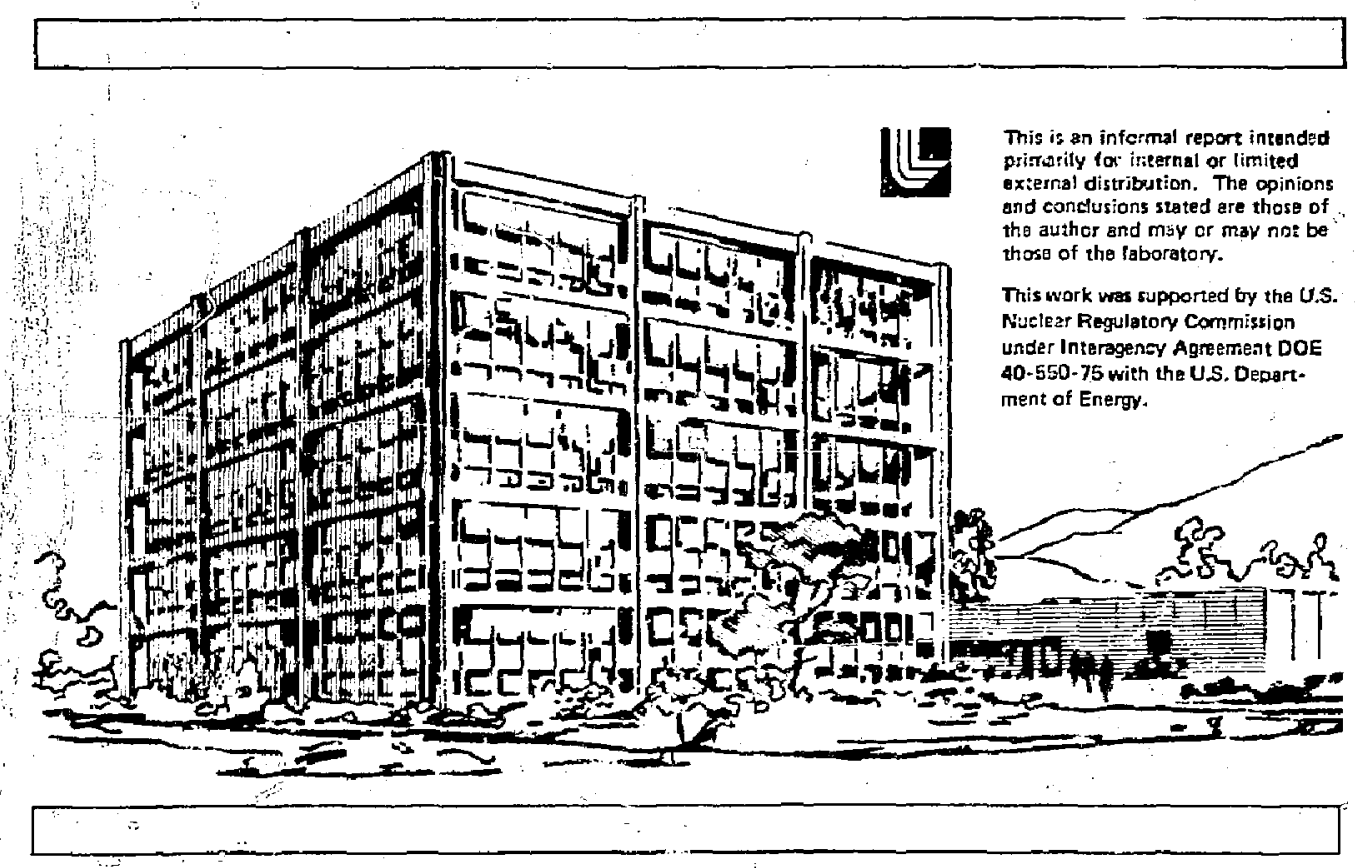

MASTER $\rightarrow$ 
BOREMORD

A computer code developed by Taylor and Brown (1967) was adapted to the Lawrence Livermore Laboratory computer network to study the imf rtant geohydrological factors associated with a nuclear waste repositozy in geologic media. The study was executed under contract to the Nuclear Regulatory Commission. To date, the author has applied the code to the simulation of generic geohydrological situations, but other potential applicatic as of the code are apparent.

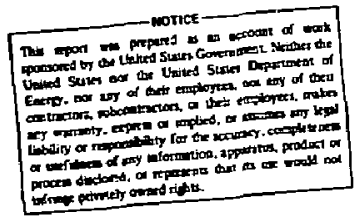


1. Finite elenent mesh of example problen . . . . . . . . . . 6

C-1. Egual potential contour with nodes . . . . . . . . . . . . 39

C-2. Equal potential contour without nodes . . . . . . . . . . . 39

c-3. Pressure contour with nodes . . . . . . . . . . . . . . 40

C-4. Presaure contour without nodes . . . . . . , . . . . . . 40

C-5. Finite-element mesh . . . . . . . . . . . . . . . . . 41 


\section{TABES OF CONTENTS}

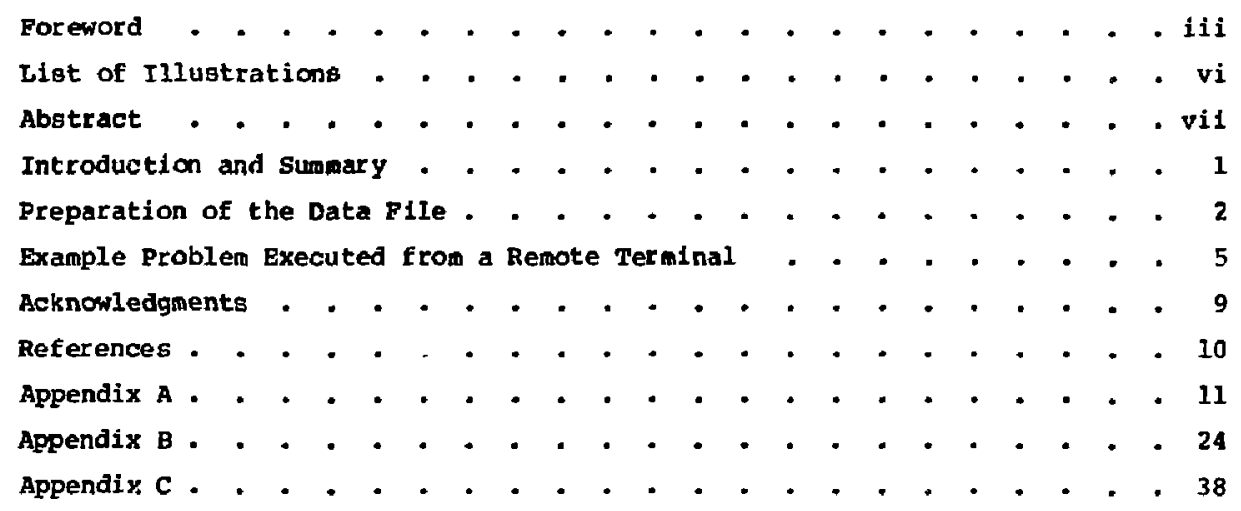




\section{ABSTRACT}

A ground-water hydrology computer code, programined by R. L. Taylor (in Proc. American Society of Civil Engineers, Journal of Hydraulics Division, 93 (HY2), PP. 25-33 (1967), has been adapted to the octopus computer system $\varepsilon^{\prime}$. Lawrence Livermore Laboratory. Using an examjle problem, this manual details the input, output, and execution options of the code. 
A computer code written by R.L. Taylor (Taylor and Brown, 1967) was adapted to study important geohydrological parameters associated with underground nuclear waste repositories. To explore the code's capabilities, the author of this manual developed an example problem that simulates conditions in the vicinity of a geologic repository.

Basically, the code calculates pressures, equipotentials, and flow vectors in two-dimensional flow problems. Flow is governed by a generalized Darcy equation:

$$
q_{i}=\frac{K_{i j}}{\mu} \quad\left\{p_{s_{j}}+F_{j}\right\} .
$$

where

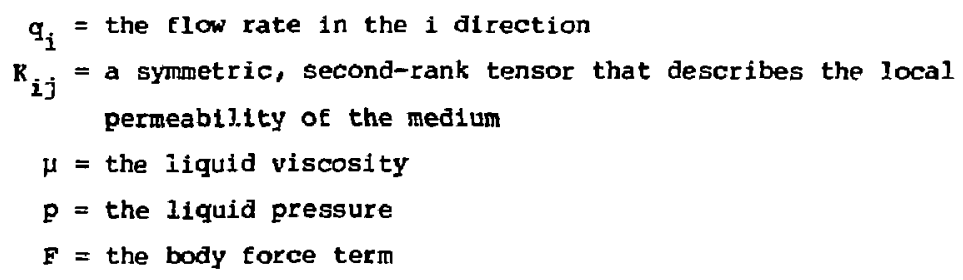

The findte element approach is used to cormulate the equations of ground-water flow and the solution is obtalned by the Rayleigh-Ritz procedure (Taylor and Brown, 1967). Both planar and axisymmetric problems with zoned heterogeneity and with isotropic or anisotropic materials (under conditions of saturated steady-state flow) can be solved; both flux anc pressure boundary conditions may be considered. The code also can solve certain unconfined fllui problens with the use of free surface boundaries. 
The finite element mesh must be built before the data deck is prepared. But, because of the flexibility in this procedure and because of the large number of avallable references on the subject (for example, pinder and Gray, 1977), we will not discuss mesh construction in this paper. The rearer should also note that this code can handl's triangular elements. Below we present a j.1st of the necessary input data, formats, and sn example problen to clarify the procedure for running this code.

Identification card (20A4)

Control card $(615,3510.0$, I5)

Number of nodes

Number of elements

Number of materials

Number of free surface correction nodes

Type of problem

(I5)

$$
\begin{aligned}
& 0=\text { Axisymmetric flow } \\
& 1=\text { Plane flow }
\end{aligned}
$$

Number of flow cards (I5)

Height for equipotential reference (F10.0)

Total available head (F10.0)

Free surface correction factor (F10.0)

Number of tterations for free surface

Material identification cards: one raterlal per card $(5 \mathrm{X}, 3 \mathrm{~F} 10.0)$

Item:

Material number (5x) for user bookkeeping

Princlpal hydraulic conductivity I (F10.0)

Principal hydraulic conductivity 2 (F10.0)

Fluid weight (F10.0)

The $I$ axis is measured with respect to $X$ (or $R$ ) 


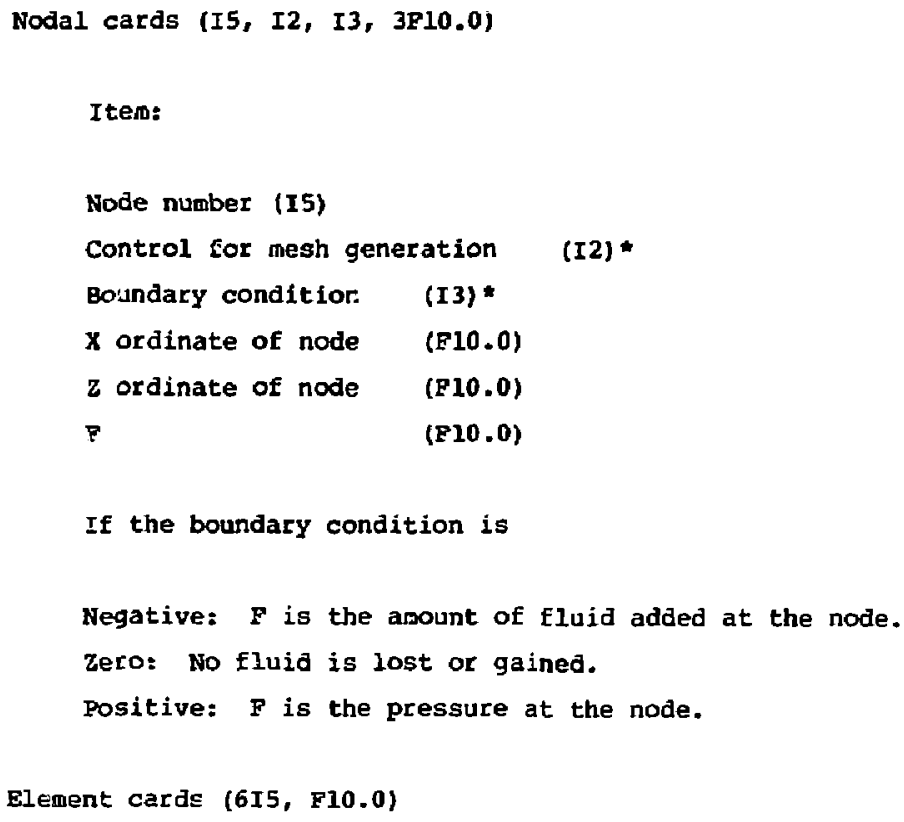

*Consult Taylor and Brown (1967) 
Distributed flow cards: one boundary per card (215, F10.0)

\section{Item:}

Node I (I5)

Node $J$ (I5)

Flow rate along Eundary (F10.0)

Free surface description: one card per free surface nods iI5, F10.0)

Item:

Node number (I5)

Correction direution in degrees with respect to the X-axis $(P 10.0)$ 
EXAMPLE PROBLEY EXECOTED FROM A REMTE TERMINAL

To complete this run of the code on the LLL oystem, four files are needed:

- GHFLW, the executable code

- UXRJ

- UXTV

- A data ingut file.

An example problem, taken from an earlier study by Naymik (1978), is oresented to demonstrate the creation of the data input file.

Figure 1 illustrates the finite elewent mesh of the example problem. Node numbering proceeds along vertical mesh lines from iottom left to top right; element numbering proceeds in the same manner. The problem (illustrated by Fig. 1) is divided into 346 elements whose shapes ar: prescribed by the coordinates of 372 nodes forming the corners.

The complete data input file for the example problem is found in Appendix A. The first $l$ ine is the problem identification. The second line is the control line. It indicates 372 nodes, 346 elements, 14 different materials, the lack of Eree surface corfection nodes, a planar solution, the lack of distributed flow conditions, a zero reference for equipotentials, the total available head of $1204.7 \mathrm{~m}$ (greatest head assigned to a node as a boundary condition), a zero free surface correction factor, and two iterations. only one iteration is required for a steady-rate solution that aoes not involve a free surface; two iterations were used as a check. 


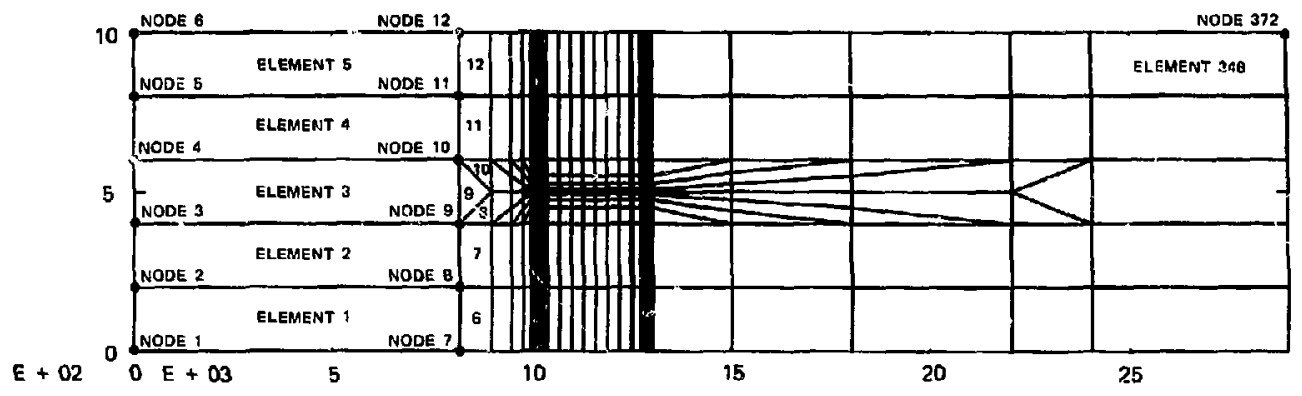

FIG. 1. Finite element mesh of example problem. 
Lines 3 through 16 are the 14 material identification Iines. Each material having different principal hydraulic conductivities is assigned an Integer (startiig with 1 and ending with the total number of naterials). The nodal information is presented on lines 1.7 through 388 in the format descrilred earlier. The hydraulic head is determined with reference to $z=0$, where $z$ is the vertical ccordinate. The horizontal coordinate is $x$. The lowest nories in the mesh have $z$-values $=0$. The nodes farthest to the left have $x$-values $=$ 0 . The element information is in 11 nes 389 through 734 . Element corners are defined by node numbers starting in the lower left corner and proceed courterclockwise around the element (for example, in Fig. 1 , element $I$ i: defined by nodes $1,7,8$, and 2 ).

Th.- following TTY inceractions are used to execute the controllee:

$\begin{array}{ll}\text { User: } & \text { GWFLOW/ } t v \\ \text { THY: } & \text { EMTER-INPUT DATA DISK FILE NAME } \\ \text { User: } & \text { Name of input file } \\ \text { TTY: } & \text { ENTER - t OF LEVELS, MAP GRID OPT, XMIN, XMAX, zMAX } \\ \text { User*: } & a, b, c, a, e \\ \text { TTY: } & \text { NLL DONE }\end{array}$

The output EIles are HSPO, JATr80DD80, and VELC TT. The HSPO f rom the example problem is presented in Appendix B. In HSPO, the fnput is printed out (in Append1X $B$ the node and element Information was onitted), foljowed by pressures, and potential values at each node. The Einal printed data are the

\footnotetext{
- The number of levels (a) refers to the number of equipotent:3I and equipressure lines desired in the plot file that are generated by the UX80LTB graphics package. The map grid options (b) are: 1 (which plots the full problem as in Fig. I) or 0 (which plots only the part of the problem between XMIN (c) and XMAX (d)). The ZMAX (e) is the largest $z$-value used in the :esh; 2HAX $=1000$ in Fig. 1. The example problem requ1red 0.2 minutes of computer time.
} 
flow rates per unit area, calculated at each element center. The horizontal flow rate (Q1) and the vertical flow rate (Q2) are components of the vector, total $Q$ and direction. The file VHLOUT contains flow rates interpolated from the element centers to the nodes.

The JATV80DD80 file can be used with UXTV and JXRJ (Blair, 1977). The file contains plots of

- equal potential contours with nodes

- equal potential contours without nodes

- pressure contours with nodes

- pressure conteurs without iodes

- the finite element mesh.

The graphics from the example problem are presented in Appendix $c$. In the example problem

- Number (t) of levels $=25$

- Map grid option $(O P T)=1$

- $\quad \mathrm{X} \div \mathrm{N}=0$

- $\operatorname{XMAX}=28942.5$

- $2 \operatorname{Max}=1000$.

For further information, contact T. G. Naymik or G. D. Mendez at Lawrence L1vermore Laboratory. 


\section{ACRNONLEDGEENTS}

The writer wishes to thank G. D. Hendez, C. D. Thorson, and S. Driess for technical assistance in applying this code. Helpful suggestions from $G$. D. Mendez and R. Store in preparing this manuscript are also apprectated. 
REFERENCES

M. Bla1r, The UXDD80 Graphics System, Lawrence Livermore Laboratory, Livermore, CA, UCID - 30146 (1977).

T. G. Naymik, An Application of a Hethod for Comparing One-Dimensional and Two-D1mensional Models of a Ground-water Flow Syst em, Lawrence Livermore Laboratory, Livermore CA. UCRL-52541 (1978) .

G. F. Pinder and w. G. Gray, Finite Element simulation in Surface and Subsurface Bydrology (Academic Press, New York, San Francisco, London, 1977).

R. L. Taylor and C. B. Brown, Darcy Flow Solutions with a Free Surface, in Proc. American society of Civil Engineers, Journal of Hydraulics Division, 93 (HY2), Pp. 25-33 (1967). 
APPENDIX A:

INPUT FOR EXAMPLE PROBLEM

This appendix contains all input data for the example problem discussed in the preceding text. The problem demonstrates the utility of a ground-water hydrology code that was originally programmed by R. L. Taylor (1967).

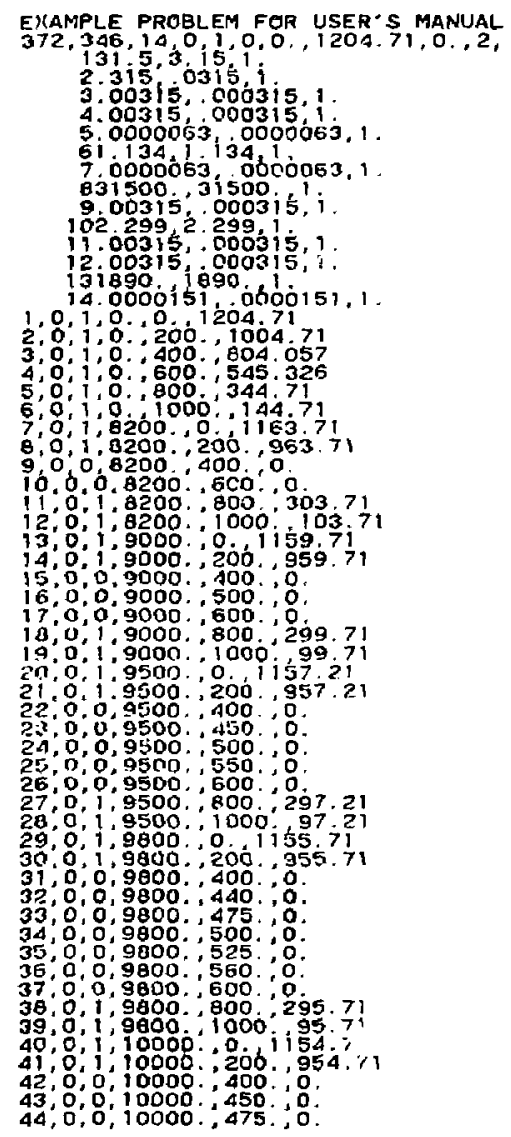




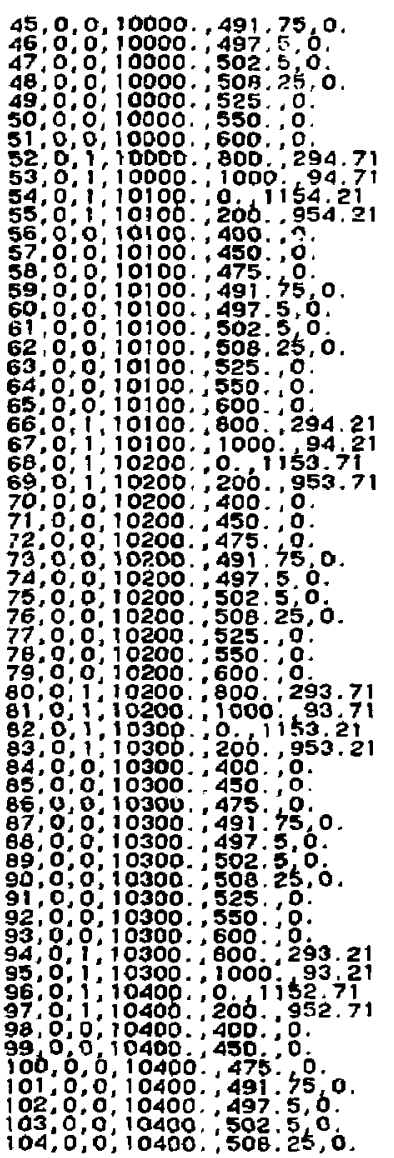




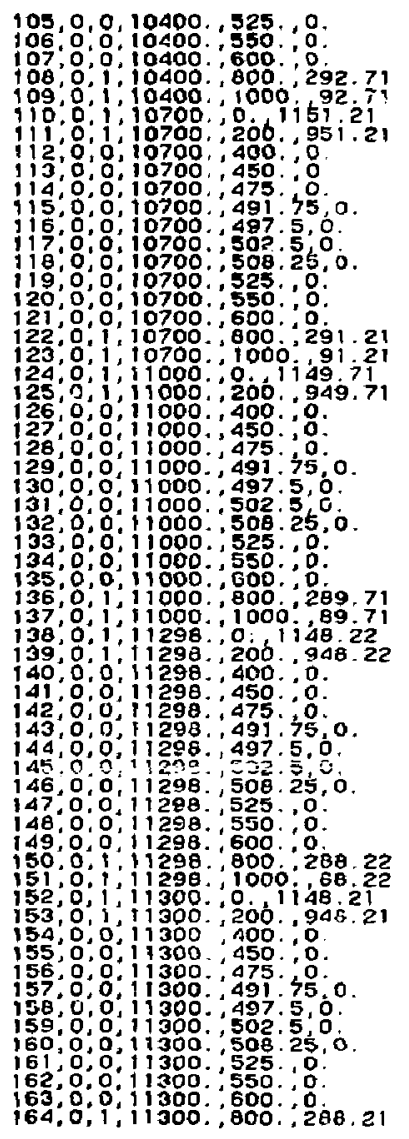




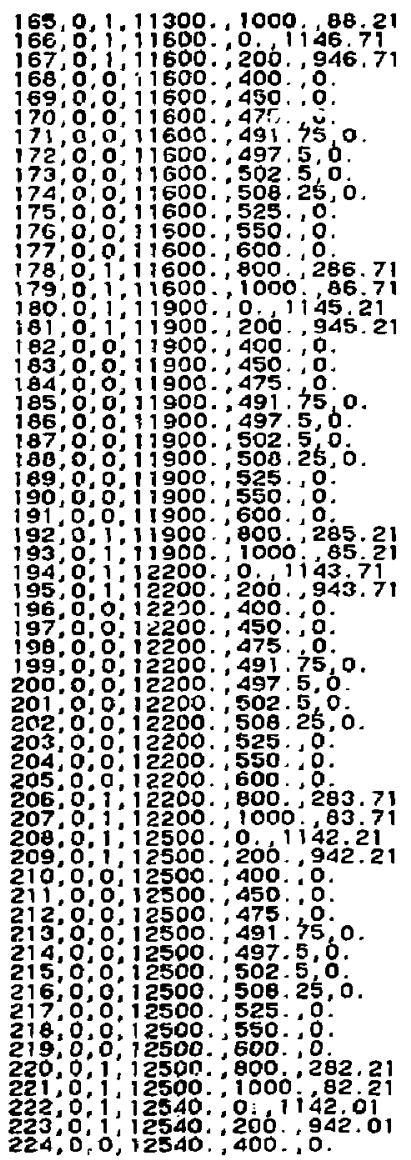




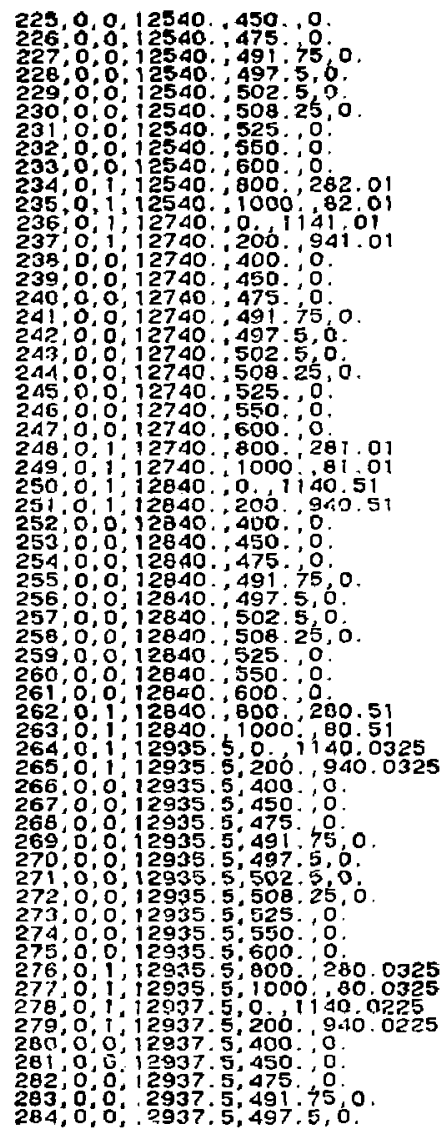




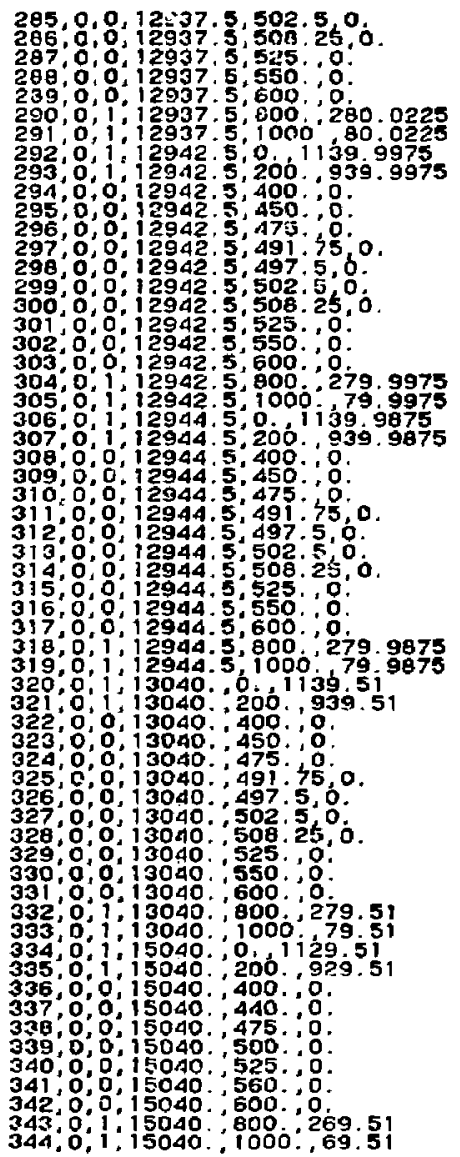




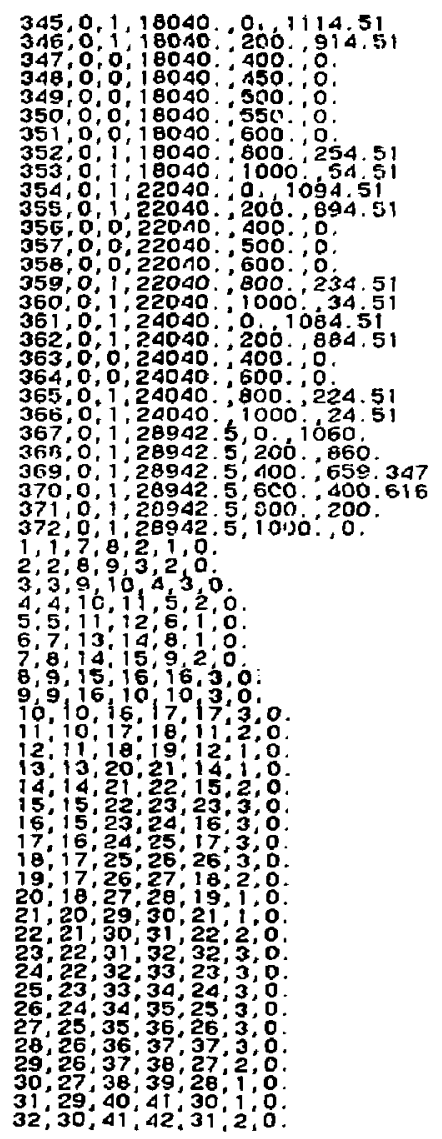


$39,91,42,43,43,3,0$.

$35,32,44,45,33,3,0$.

$36,33,45,46,34,3,0$.

37, 39, 46, 47, 47: 3 ; 0

$38,34,47,48,35,2,0$.

$39,35,48,49,36,2,0$.

$41 ; 37,50 ; 61 ; 51 ; 3 ; 0$;

$42,37,51,52,39 ; 2,0$.

$44,40,54,55,41,1 \%$

$45,41,55,56,42,2,0$.

$46,42,56,57,43,3,0$.

$47,43,57.58,44,3,0$.

$49,45,59,60 ; 46,8,0$.

51,$47 ; 61,62 ; 48 ; 8 ; 0$.

53,$49 ; 63,64 ; 50 ; 12$;

54,$50 ; 64,65,51 ; 3,6$.

$55,51,65,65,52,2,0$.

$56,52,66,67,53,1,0$.

$57,54,68,69,55,1,0$.

$59,50,79,57,0$

$60,57,71,72,58,3,0$.

$61,58,72,73,59,9,0$.

$62,59,73,74,60,0.0$.

$63,60,74,75,61,4,0$.

65,62:76,77,63;11,0

$66,63,77,78,64,12,0$.

$67,64,78,73,65,3,0$.

60.65.79:80.66,2:0.

5.6.,00,

$71,69,83,64,70,2 \% 0$.

$72,70,84,85,71,3,0$.

$73,71,85,06,72,3,0$.

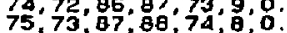

76; 74;88;09;75; 4 ;0.

$77,75,89 ; 90 ; 76,8,0$.

78:76;90,91,77, 11,

80; 78;92:93;79; 3.0 .

81,$79 ; 93 ; 94 ; 80,2,0$.

82,$80 ; 94 ; 95,81,1,0$.

$83,82,96,97,83,1,0$.

95, 84:98; $99,85,3,0$.

$86,85,99,106$

$87,86,106,19,87,9,0$

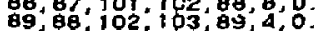

90,$89 ; 103 ; 104 ; 90,8 ; 0$

92, 90 ; 105, 105, $102,12,0$. 


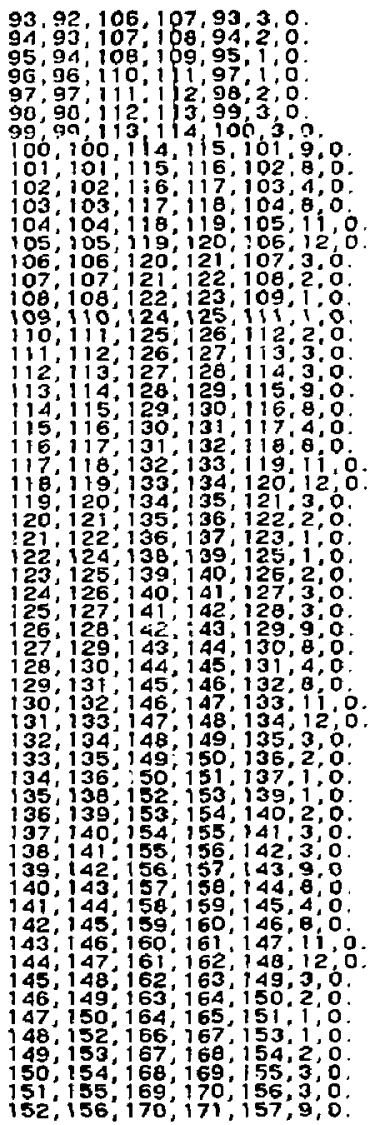




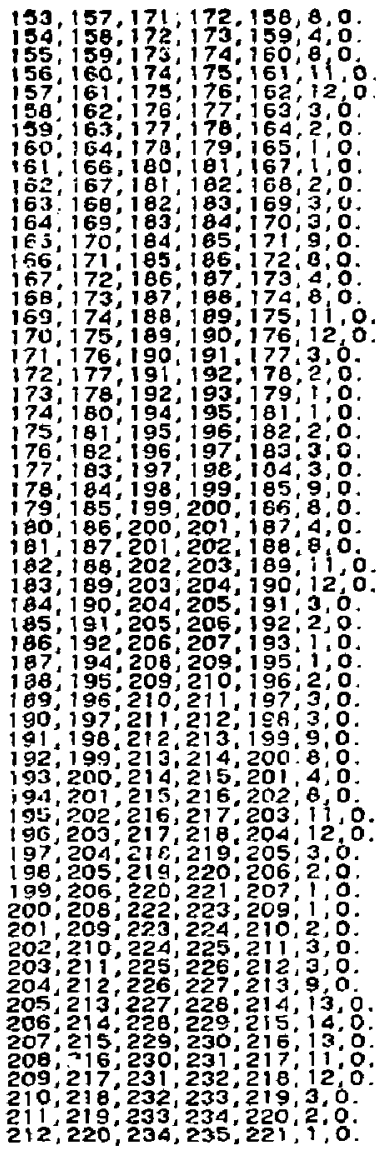




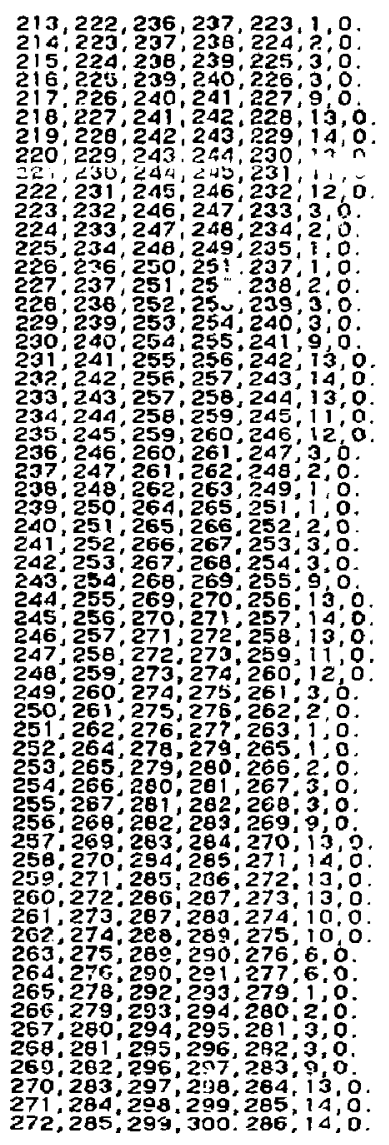




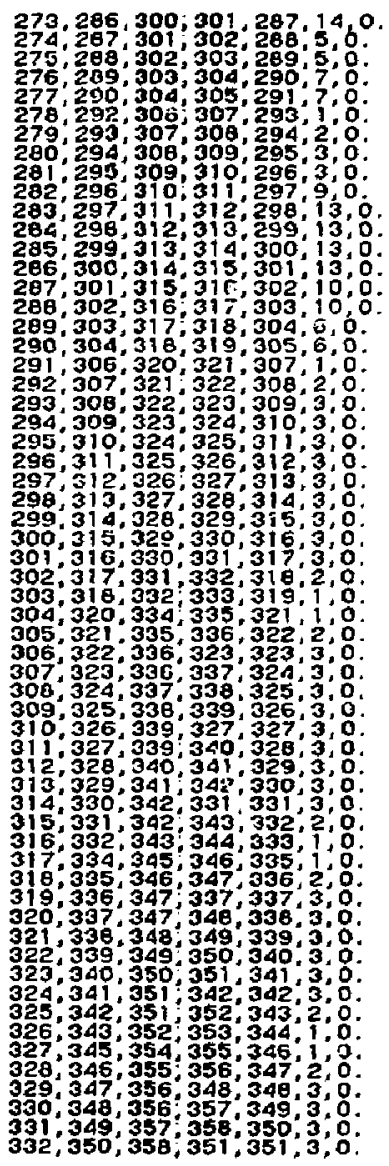




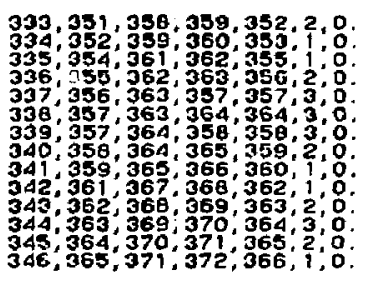


APPENDIX B:

PRINTED OUTPUT FROM THE EXAMPLE PROBLEM (HIGH SPEED FILE)

Thts appendix contalns computer generated output $f r o m$ an example problen in ground-water hydrology. The problem was solved with a computer code originally prepared by R. L. Taylor (1967) and later modified for use at Lawrence Livermore Laboratory.

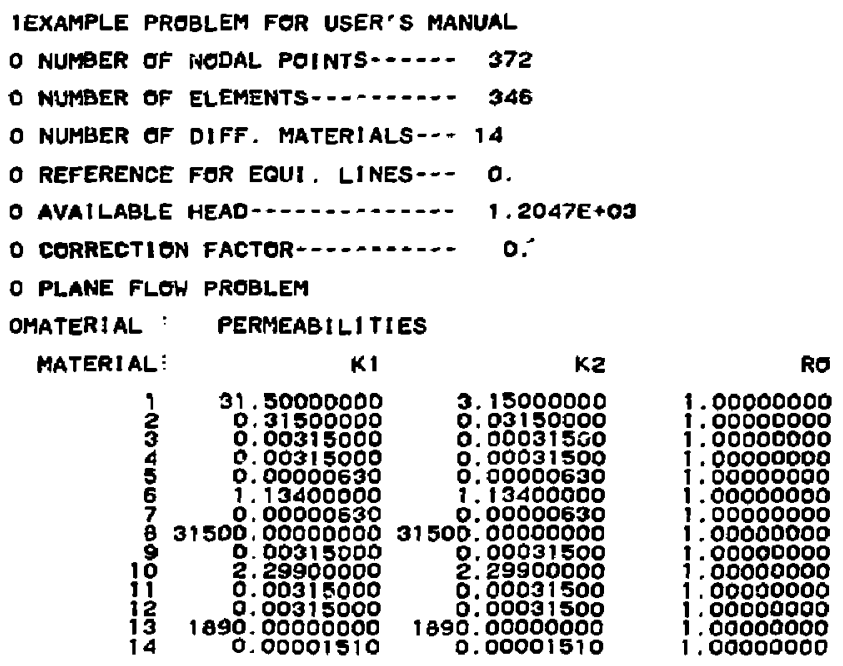




\begin{tabular}{|c|c|c|}
\hline DNODE & PRESSURE & EQUIPOT LINE \\
\hline $\begin{array}{l}1 \\
2 \\
3 \\
4 \\
5 \\
6 \\
7 \\
8 \\
9 \\
10 \\
11 \\
12 \\
13 \\
14 \\
15 \\
16 \\
17 \\
18 \\
19 \\
20 \\
21 \\
22 \\
23 \\
24 \\
25 \\
26 \\
27 \\
28 \\
29 \\
30 \\
31 \\
32 \\
33 \\
34 \\
35 \\
36 \\
37 \\
38 \\
39 \\
40 \\
41 \\
42 \\
43 \\
44 \\
45 \\
46 \\
47 \\
48 \\
49 \\
50 \\
51 \\
52 \\
53\end{array}$ & 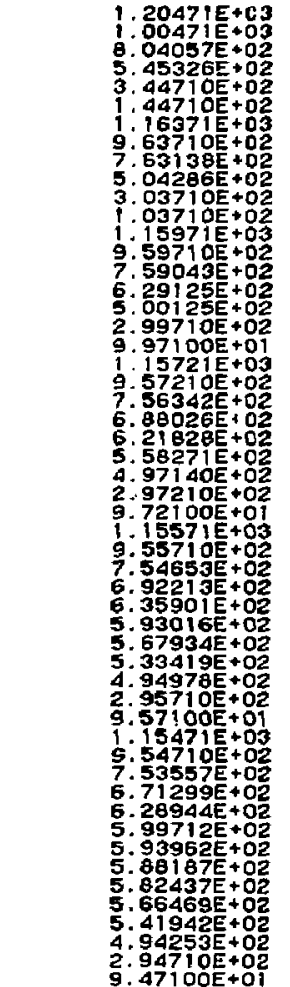 & 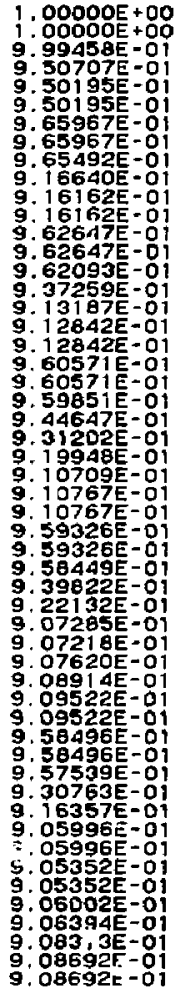 \\
\hline
\end{tabular}




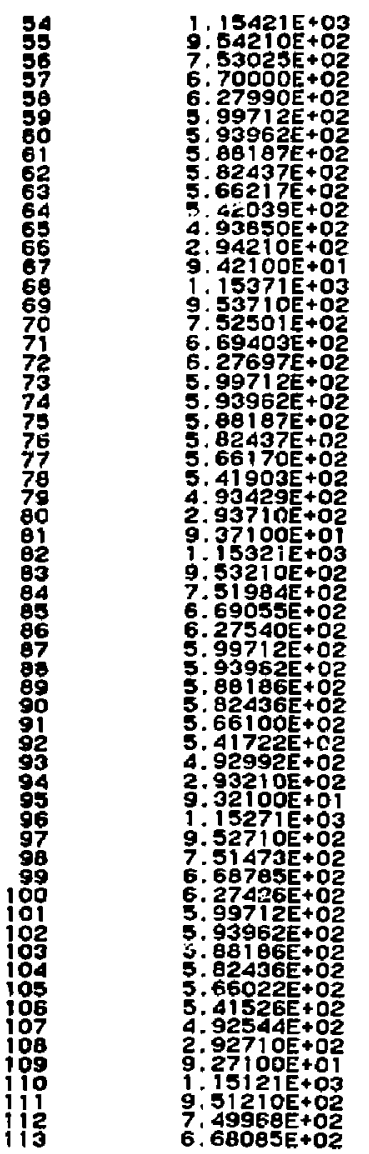

9. 58081E-01

9. 5BOBIE-D

9.57097E-

9. 29685 -O

9, $05996-0$

9.05996E-ô

9.05352E-ם1

9. $05352 E-01$

9.05792E-a

9.06475E-

9.07978E-0

'. $00277 \mathrm{~g}-01$

9.5666 -

9. $576665-01$

9. $56662 E-01$

$9.29109 \mathrm{E}-0$

g. I5j2ie-oi

$9.05996 \mathrm{E}-\mathrm{a}$

9.05996E-01

$9.05352 E-0$

9 , 05352E-

$9.05753 \mathrm{E}-0$

$9.06362 \mathrm{E}-01$

$9.07628 \mathrm{E}$

9.0786 -

9.57251E-oi

9.57251 -01

$9.57251 E-01$

9.28900E-ó

9.15191E-O

9.05996E-0

9.05996 -01

9. O3

9.05696-D

9. O6212E-O1

9.07266 -01

9.07447E-O

9 . $5636 E-0$.

9. $56836 E=01$

9. $58836 E-01$

9. 35B1 OE-OI

9. $28676 E=01$

9.

9. $05996 \mathrm{E}-01$

9. of3

$9.05631 E-01$

9.06048E-01

9.07032E-ด1

9. 07032E-01

$9.55591 \mathrm{E}-01$

9. $54591=01$

9. $54560 E-01$ 
9.53iole-ol

$9.52103 E-01$

9.26977E-01

9. $4495 \mathrm{E}$ -

$9.05995 E-01$

9. $05351 E-01$

9.05351E-O

9. $04995 \mathrm{E}-\mathrm{O} 1$

9. $04463 E-01$

9.03395E-O

9. $03296 E-01$

.51856E-O

$9.51856 \mathrm{E}-\mathrm{O}$

9. $50885 \mathrm{E}-0$

9. $264225=01$

$9.14190 E-01$

9. 05995 E

9.05350E-01 


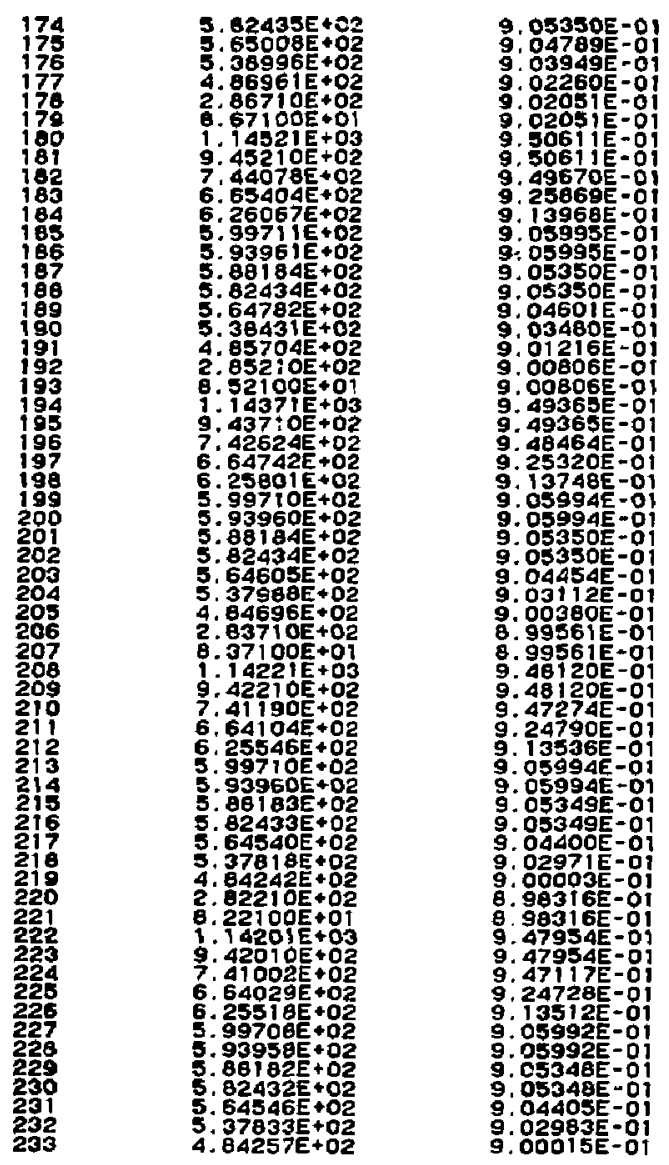




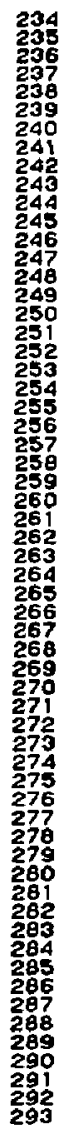

2. 82010E +02 1. Ta101E+03 9.41 OIOE +22 $7.40070 \mathrm{O}+2$ G. $63968 E+02$ $6.25543 E+02$ $5.99701 E+02$ $5.93951 E+02$ . $5.64675 \mathrm{t}+02$ $5.38134 E+0$ . 4.0474 . $10100 \mathrm{O}+01$ 1. $14051 E+03$ 9. $40510 E+02$ $7.39614 E+02$ 6. $64719 E+02$ $6.26000 \mathrm{E}+02$ $5.99697 E+02$ $5.93947 E+02$ $5.88175 E+02$ $5.82425 E+02$ $5.64967 E+02$ $5.38540 E+02$ $4.85282 E+02$ 2. BO5 10E+02 $8.05100 E+01$ 1. $14003 E+03$ 9. $40033 E+02$ . $39132+02$ 7. $39182 E+02$ 6. $6695 \mathrm{SE}+02$ 5. $99693 \mathrm{E}+02$ 5. $93943 E+02$ 5. 8 172E +02 S. 82422E+02 $5.65671 \mathrm{E}+02$ $5.39150 E+02$ 4.861 I $5 E+02$ 2. $80032 \mathrm{E}+0$ 代 Q. $00325 E+01$ 1. $14002 E+03$ $9.40023 E+02$ 9. $39023 E+02$ 7. 39173E+02 $6.67021 \mathrm{E}+02$ 5. $28493 E+02$ 5. $93943 E+02$ 5.8 1 $72 \mathrm{C}+02$ $5.82422 \mathrm{E}+\mathrm{O} 2$ $5.65671 E+02$ $5.39149 E+02$ 4. $4.86119=02$ 2. 1. $00225 E+01$ 1. $14090 E+03$
$9.39998 E+02$

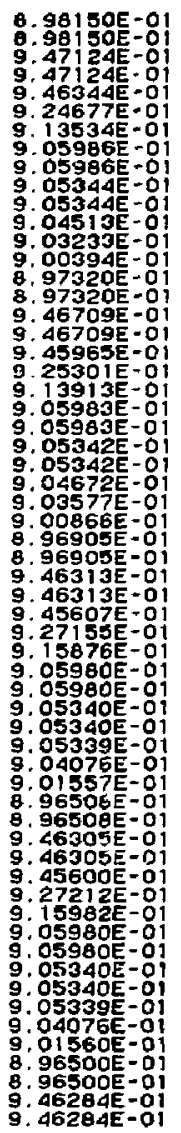



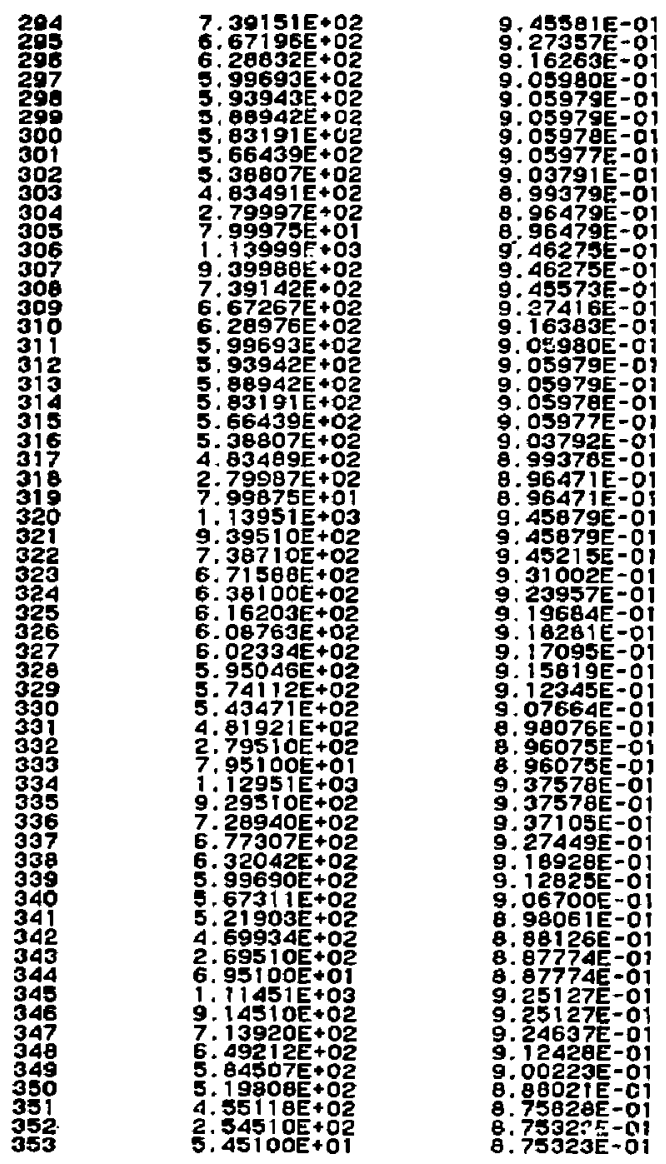
IEXample PRgBlem fur user's manual OELEMENT FEGHS

\begin{tabular}{|c|c|}
\hline 01 & 02 \\
\hline 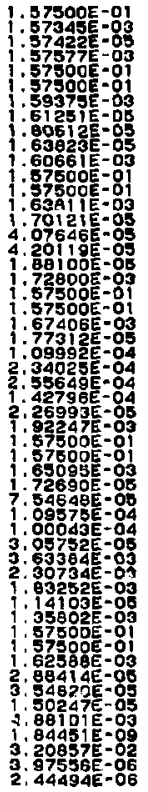 & 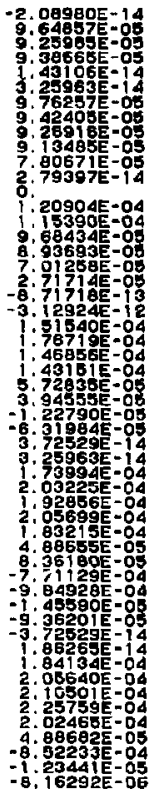 \\
\hline
\end{tabular}

ANO
$0:$
$0:$
$0:$
$0:$
$0:$
$0:$
$0:$
$0:$
$0:$
$0:$
$0:$
$0:$
$0:$
$0:$
$0:$
$0:$
$0:$
$0:$
$0:$
$0:$
$0:$
$0:$
$0:$
$0:$
$0:$
$0:$
$0:$
$0:$
$0:$
$0:$
$0:$

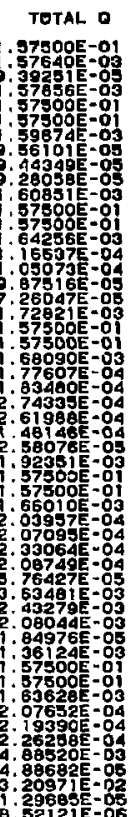

DI RECTI ON

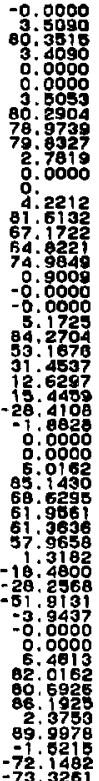




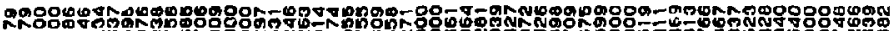

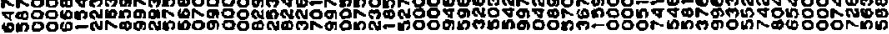
óvónó

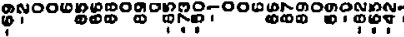

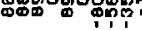

gogogono
\end{abstract}

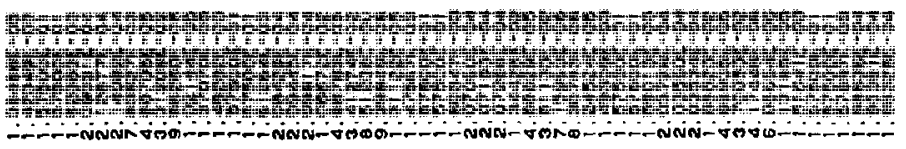

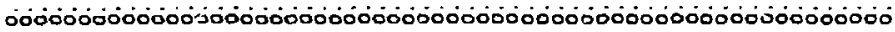
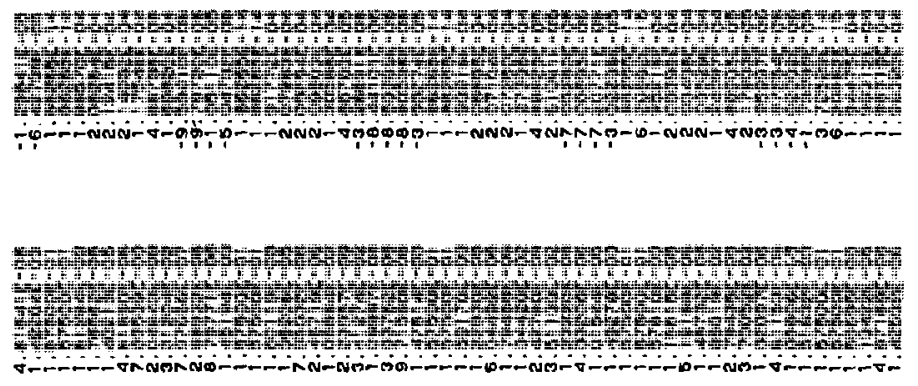

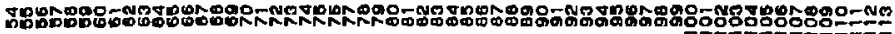



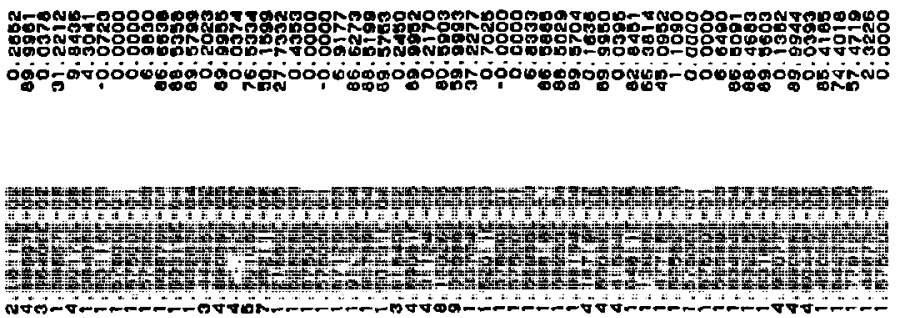

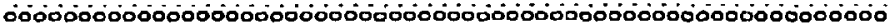

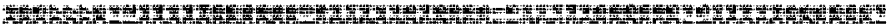
7 .

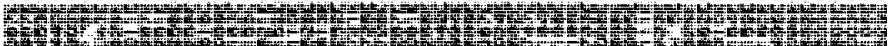
4 th

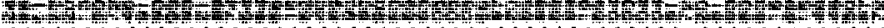

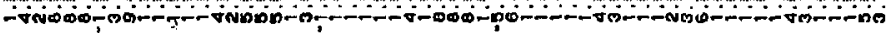

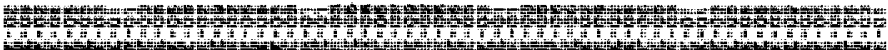

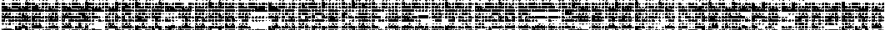

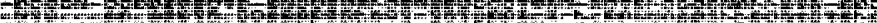

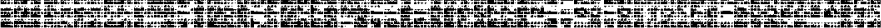

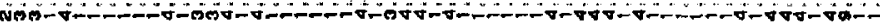

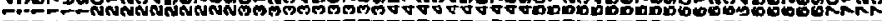



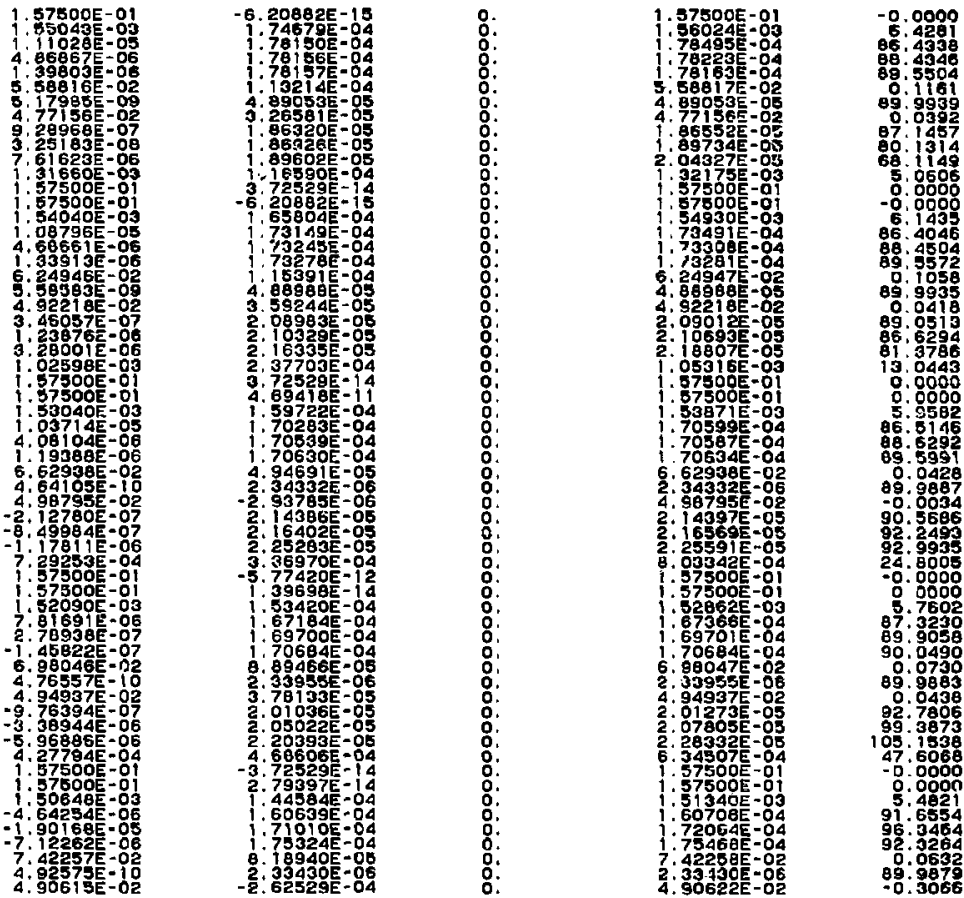

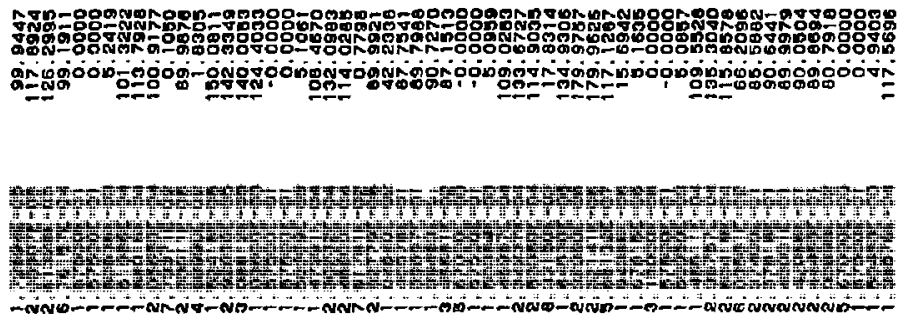

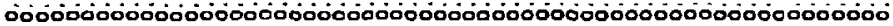
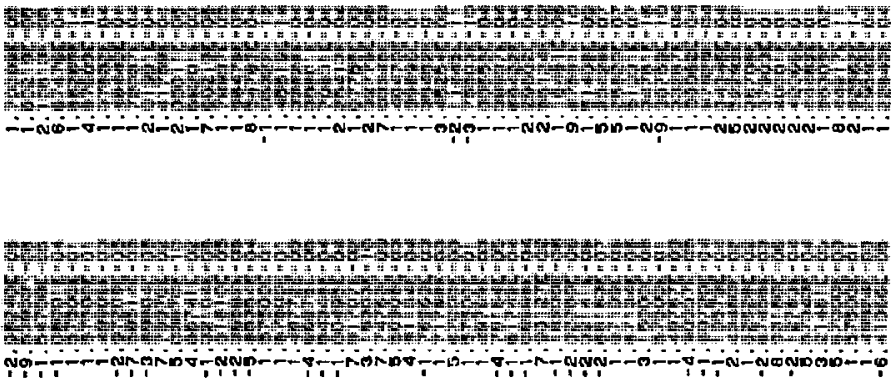

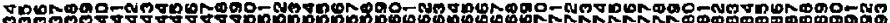
ถูกำ 


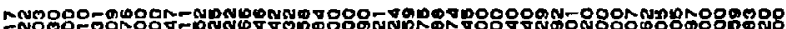

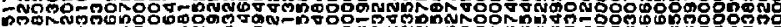
คึ.

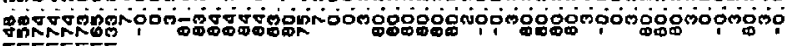

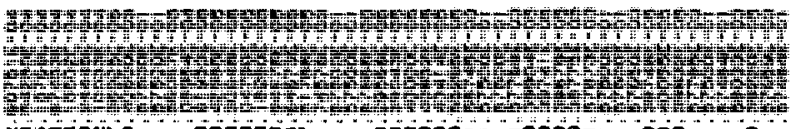

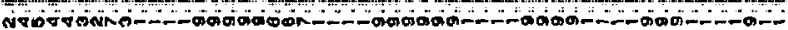

D000000000000000000000000000000000000000000000000000000000

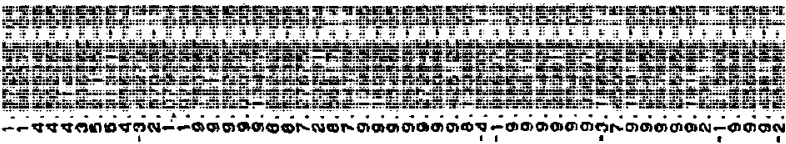

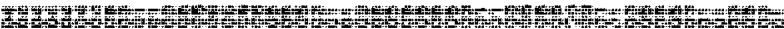

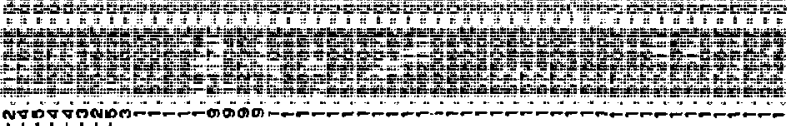

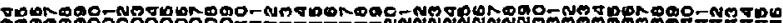

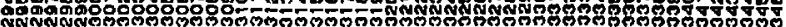




\section{APPENDIX C:}

\section{EXAMPLE PROBLEN GRAPHICS}

This append1x contains computer-generated graphic displays of output fron an example problem in ground-water hydrology described in the preceding text. The problem was solved with a computer code originally prepared by R.L. Taylor (1967) and later modified for use at Lawrence Livermore Laboratory. 


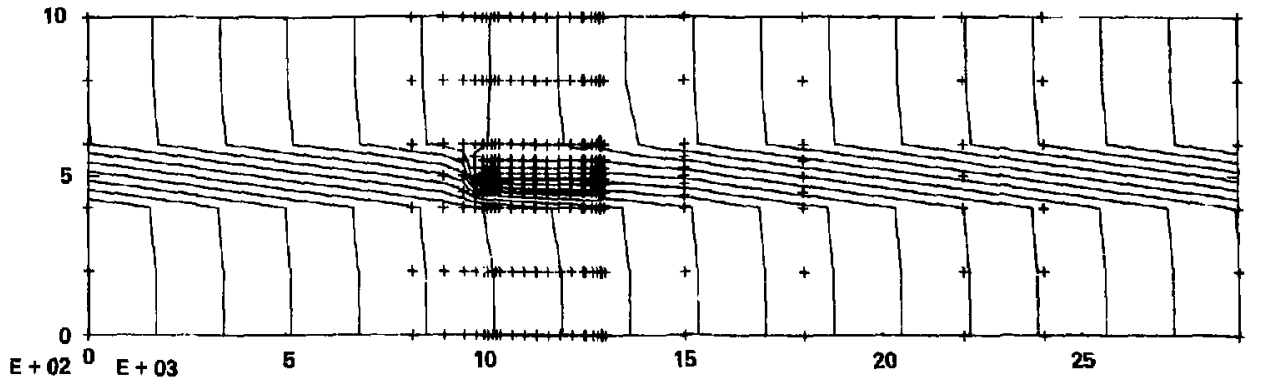

FIG. C-1. Equal potential contour with nodes.

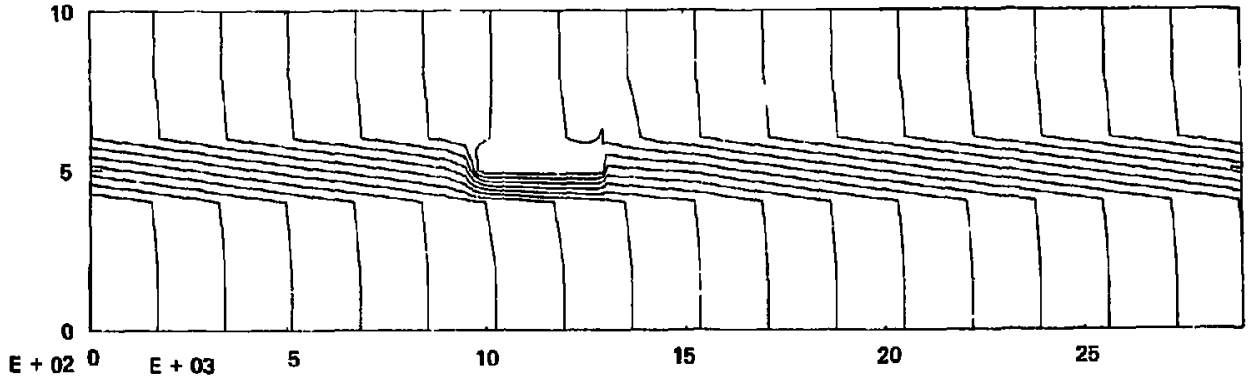

FIG. C-2. Equal potentlal contour without nories. 


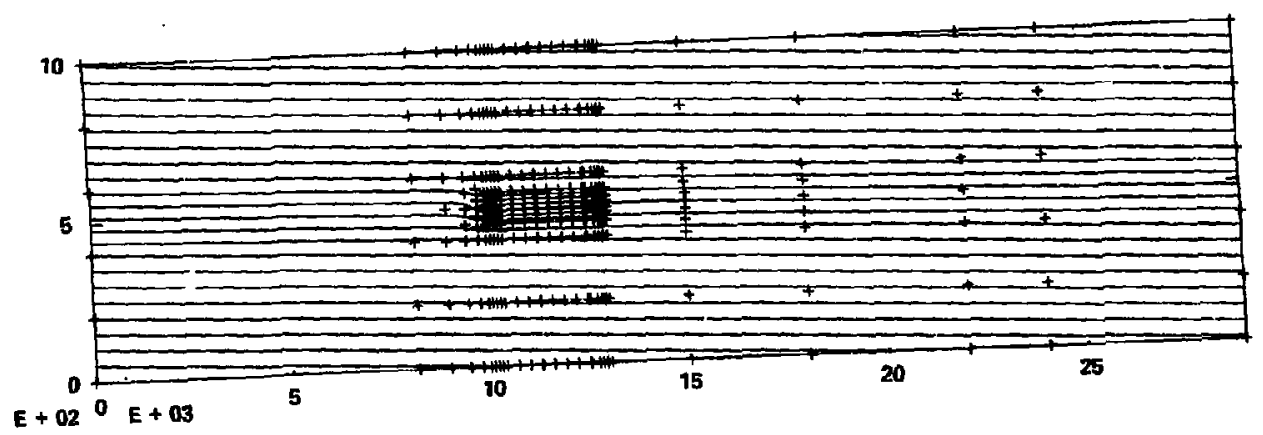

EIG. C-3. Pressure contour with norles.

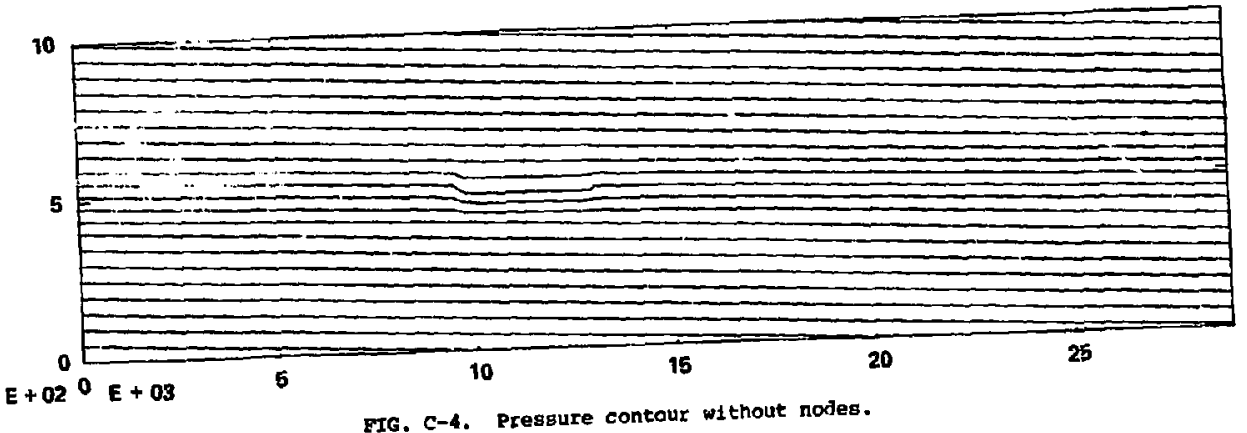

FIG. C-4. Preggure contour without nodes. 


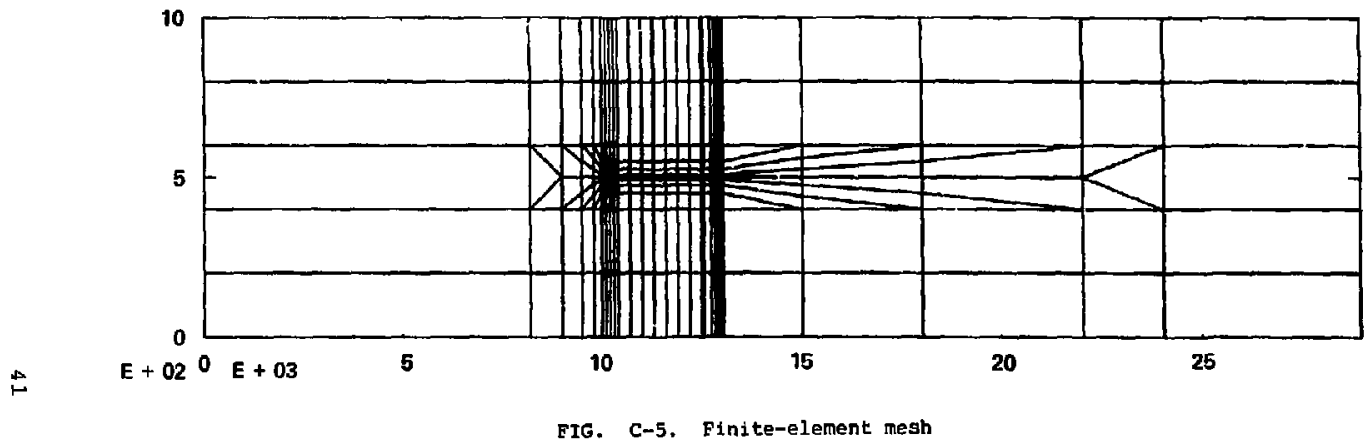

